\title{
Medical Image of the Week: Pulsus Paradoxus
}

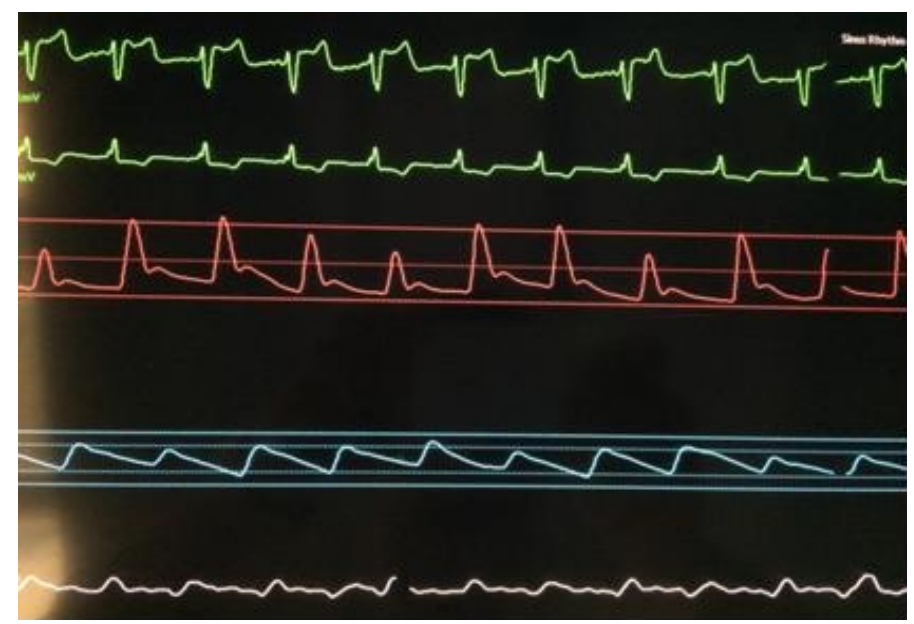

Figure 1. Arterial line (red) showing pulsus paradoxus.

A 75 year-old man was admitted for suspected septic shock and acute renal failure requiring hemodialysis. He did not required mechanical ventilation. An arterial line was placed and he was found to have pulsus paradoxus (Figure 1). A transthoracic echocardiogram showed early right atrial diastolic collapse consistent with cardiac tamponade and he underwent a pericardial window.

Pulsus paradoxus is the drop in more than $10 \mathrm{~mm} \mathrm{Hg}$ of systolic pressure during the inspiratory phase (1). Causes of pulsus paradoxus include cardiac tamponade, constrictive pericarditis, severe asthma and chronic obstructive pulmonary disease, restrictive cardiomyopathy, tension pneumothorax, tracheal compression, and circulatory shock (2). With early recognition of this clinical sign, prompt treatment of the underlying etiology can produce a more desirable outcome.

Choua Thao MD' ${ }^{1}$, Mohanad Hasan $\mathrm{MD}^{1}$, Hamayon Babary $\mathrm{MD}^{1}$, and Carmen Luraschi $\mathrm{MD}^{2}$

University of Nevada School of Medicine: Las Vegas

${ }^{1}$ Department of Internal Medicine

${ }^{2}$ Division of Pulmonary and Critical Care

Las Vegas, NV

\section{References}

1. Hamzaoui O, Monnet X, Teboul JL. Pulsus paradoxus. Eur Respir J. 2013;42(6):1696-705 [CrossRef] [PubMed]

2. Swami A, Spodick DH. Pulsus paradoxus in cardiac tamponade: a pathophysiology continuum. Clin Cardiol. 2003;26(5):215-7. [CrossRef] [PubMed] 